\title{
Utilização de um veículo aéreo não-tripulado em atividades de imageamento georeferenciado
}

\author{
On the use of unmanned aerial vehicle for acquisition of georrefecend image data
}

\author{
Fabrício Ardais Medeiros ${ }^{\mathrm{I}}$ Airton dos Santos Alonço ${ }^{\mathrm{II}}$ Mônica Regina Gonzatti Balestra ${ }^{\mathrm{I}}$ \\ Vilnei de Oliveira Dias ${ }^{\text {II }}$ Mário Luiz Landerhal Júnior ${ }^{I}$
} \begin{abstract}
subsídios para propor um procedimento alternativo para aquisição de dados, telemetria, monitoramento $e$ georeferenciamento das atividades agrícolas, por meio da acoplagem de equipamentos eletrônicos a um Veículo Aéreo Não-Tripulado (VANT). Para tal, foi desenvolvido um VANT na Universidade Federal de Santa Maria, no qual foram acoplados equipamentos para a coleta de imagens e a aquisição de pontos de referência. $O$ equipamento desenvolvido mostrou imenso potencial para ser utilizado como ferramenta auxiliar na localização de áreas com falhas de germinação, na infestação de invasoras e no mapeamento de área. O maior entrave a um melhor emprego deste equipamento refere-se à baixa qualidade das imagens geradas, mostrando a necessidade de reavaliações do aparato utilizado.
\end{abstract}

Palavras-chave: engenharia agrícola, agricultura de precisão, sensoriamento remoto, imagens aéreas.

\section{ABSTRACT}

The aim of this study consisted in developing and testing an alternative procedure for data acquisition, telemetry, monitoring and geo-referencing in agricultural fields. The proposed approach was implemented by placing dedicated electronic gear onboard Unmanned Aerial Vehicles (UAV). For this purpose an UAV was assembled at the Federal University in Santa Maria, Brazil and equipped with the required hardware for image and control points acquisition. Tests have shown that the proposed approach can be regarded as a valuable tool to detect areas affected by faulty germination, weed infestation and mapping in general. The tests have also shown that poor quality of the acquired image data was the main drawback in the equipment onboard the UAV, pointing to the need to reevaluate the system with regard to this particular aspect.
Key words: agricultural engineering, precision farming, remote sensing, aerial images.

O desenvolvimento de Veículos Aéreos Não-Tripulados (VANT’s) vem se firmando como uma importante opção na agricultura de precisão, visto que a utilização e a aplicação de novos conhecimentos no meio rural auxiliam o produtor a identificar estratégias que possam aumentar a eficiência no gerenciamento da agricultura, maximizando a rentabilidade das colheitas e tornando o agronegócio mais competitivo ALONÇO et al. (2005). A introdução do conceito de agricultura de precisão em propriedades onde se tem como objetivo maximizar os lucros e minimizar os danos ambientais é imprescindível (TSCHIEDEL \& FERREIRA, 2002). Para os autores, com o advento deste conceito, será possível um maior controle sobre as possíveis causas na redução da produtividade e/ou do dano ambiental.

No Brasil, os primeiros relatos de VANT's ocorreram na década de 80, quando o Centro Técnico Aeroespacial (CTA) desenvolveu o projeto Acauã. Atualmente, os projetos visando o desenvolvimento de VANT's autônomos são conduzidos pelos institutos de pesquisa CTA e Centro de Pesquisas Renato Archer (CenPRA). Dessa forma, o processo de identificação de anormalidades nas lavouras ou no mapa de produtividade é um ótimo referencial para iniciar a agricultura de precisão. ANTUNIASSI \& SALVADOR

\footnotetext{
ILaboratório de Segurança e Ergonomia,Universidade Federal de Santa Maria (UFSM), Santa Maria, RS, Brasil.
}

IIPrograma de Pós-graduação de Engenharia Agrícola, UFSM, Santa Maria, RS, Brasil. 
(2002) relatam que a coleta de imagens para a identificação de manchas nas lavouras pode ser obtida de vários tipos de plataforma, tais como aeromodelos, balões e aeronaves de pequeno porte. Segundo MOLIN (2000), as imagens aéreas de satélites e a videografia são ferramentas que também têm um grande potencial para identificação de manchas existentes nas lavouras, infestações de plantas daninhas, topografia e geração de mapas de produtividade. Todavia, existem limitações e erros, sendo necessárias correções preliminares dos dados, antes de transformá-los em mapas. De acordo com MOREIRA (2003), na agricultura, as imagens aéreas são utilizadas no mapeamento de culturas, na avaliação de áreas cultivadas, na detecção de áreas afetadas, em cadastros rurais e no mapeamento de solo.

O presente trabalho teve o propósito de desenvolver um procedimento alternativo para a aquisição de dados e telemetria das atividades agrícolas com um Veículo Aéreo Não-Tripulado.

Nesse trabalho foi utilizado um veículo aéreo não-tripulado descrito em ALONÇO et al. (2005), em que foram acoplados equipamentos para a coleta de imagens e aquisição de pontos de referência. A coleta de imagens foi realizada no dia 16/12/2006 a partir das 11h30min, na Universidade Federal de Santa Maria, Santa Maria - RS, coordenadas geográficas 2944'16” Latitude Sul e 53'35'32”' Longitude Oeste de Greenwich, em área com cultivo de soja em sistema de semeadura direta. As condições climáticas no momento do vôo eram propícias, com velocidade média do vento de $2 \mathrm{~m}$ $\mathrm{s}^{-1}$, estando dentro do limite máximo de $5 \mathrm{~m} \mathrm{~s}^{-1}$, dia ensolarado sem a presença de nuvens, facilitando a visualização do VANT e melhorando a qualidade das imagens obtidas.

Para a aquisição de imagens, foi utilizada uma câmera digital Sony ${ }^{\circledR}$ modelo CyberShot P-93 com resolução de 5 milhões de pixels (MP) e um cartão de armazenamento Memory Stick com capacidade de $1024 \mathrm{Mb}$, que possui espaço suficiente para a armazenagem de aproximadamente 640 imagens. A aquisição de imagens pela máquina fotográfica digital foi feita a partir da excitação do sensor Dispositivo de Carga Acoplado - Charge-Coupled Device (CCD), em que cada ponto luminoso da imagem captado pelo sensor eletrônico denomina-se pixel e o arranjo ordenado de pixels de diferentes intensidades de cor forma a imagem digital.

Para obter as coordenadas relativas à área sobrevoada, foram utilizados de forma integrada um data link, um GPS e um equipamento Overlay, sendo possível assim obter as coordenadas em tempo real na base, por meio de um monitor de TV. O sistema consiste em uma câmera filmadora com sensor CCD com resolução de 380 linhas, comumente utilizada em circuitos fechados de TV, ligada a um dispositivo responsável pela sobreposição de uma camada de vídeo (Blackbox Overlay) contendo as coordenadas da imagem que está sendo visualizada. É evidente a necessidade de ligação de um aparelho Sistema de Posicionamento Global (GPS) no Blackbox para que esta seja sua referência de coordenadas. Como resultado desta ligação, há a imagem de vídeo obtida da câmera, somada a sua coordenada atual, sendo renovada uma vez a cada segundo de acordo com a coordenada recebida do aparelho GPS. Esta imagem composta, enviada à estação base no solo por meio de um transmissor de radiofreqüência, foi visualizada em um monitor e instantaneamente gravada em mídia magnética. De acordo com as imagens recebidas e observadas pelo monitor, foi possível decidir se há ou não necessidade de aquisição de imagens estáticas com qualidade superior à observada em movimento. Caso houvesse necessidade, um botão era acionado no controle remoto e a máquina fotográfica digital fixada no VANT capturava a foto no instante desejado. A imagem selecionada após triagem foi obtida a uma altura de 276m, cobrindo uma área de 4,24 hectares, conforme figura 1 .

No primeiro vôo, os equipamentos de bordo transmitiram as informações requeridas em tempo real e, por meio do software TrackMaker ${ }^{\circledR}$, as informações obtidas foram decodificadas e integralizadas. Foram inseridas as coordenadas dos pontos utilizados de referência na imagem e foi demonstrado que, por meio deste tratamento, foi possível também determinar a altura de vôo, as dimensões da imagem e a área de cobertura. Em relação à decolagem e ao pouso, o teste foi realizado em estrada de chão batido, tendo o VANT atingido o ponto de decolagem à velocidade de $15 \mathrm{~m} \mathrm{~s}^{-1}$, porém, o vento foi desconsiderado e a decolagem foi realizada em aclive. Os testes, levando em consideração o vento, foram realizados em uma superfície plana, com cobertura de vegetação rasteira densa, e a velocidade do vento oscilava em torno de $2 \mathrm{~m} \mathrm{~s}^{-1}$, sendo que o protótipo atingiu a velocidade de decolagem em $9 \mathrm{~m} \mathrm{~s}^{-1}$, com saída de rotação máxima.

A técnica videográfica para o monitoramento de áreas e o levantamento de manchas nas áreas cultivadas, com a utilização dos instrumentos de transmissão no monitoramento aéreo utilizados no protótipo, apresentaram resultados satisfatórios devido a quantidades de informações obtidas, advindas da cultura. O sistema de posicionamento do VANT, transmitido por meio do Ovelay acoplado no GPS e ao Data Link, possibilitou determinar o posicionamento 


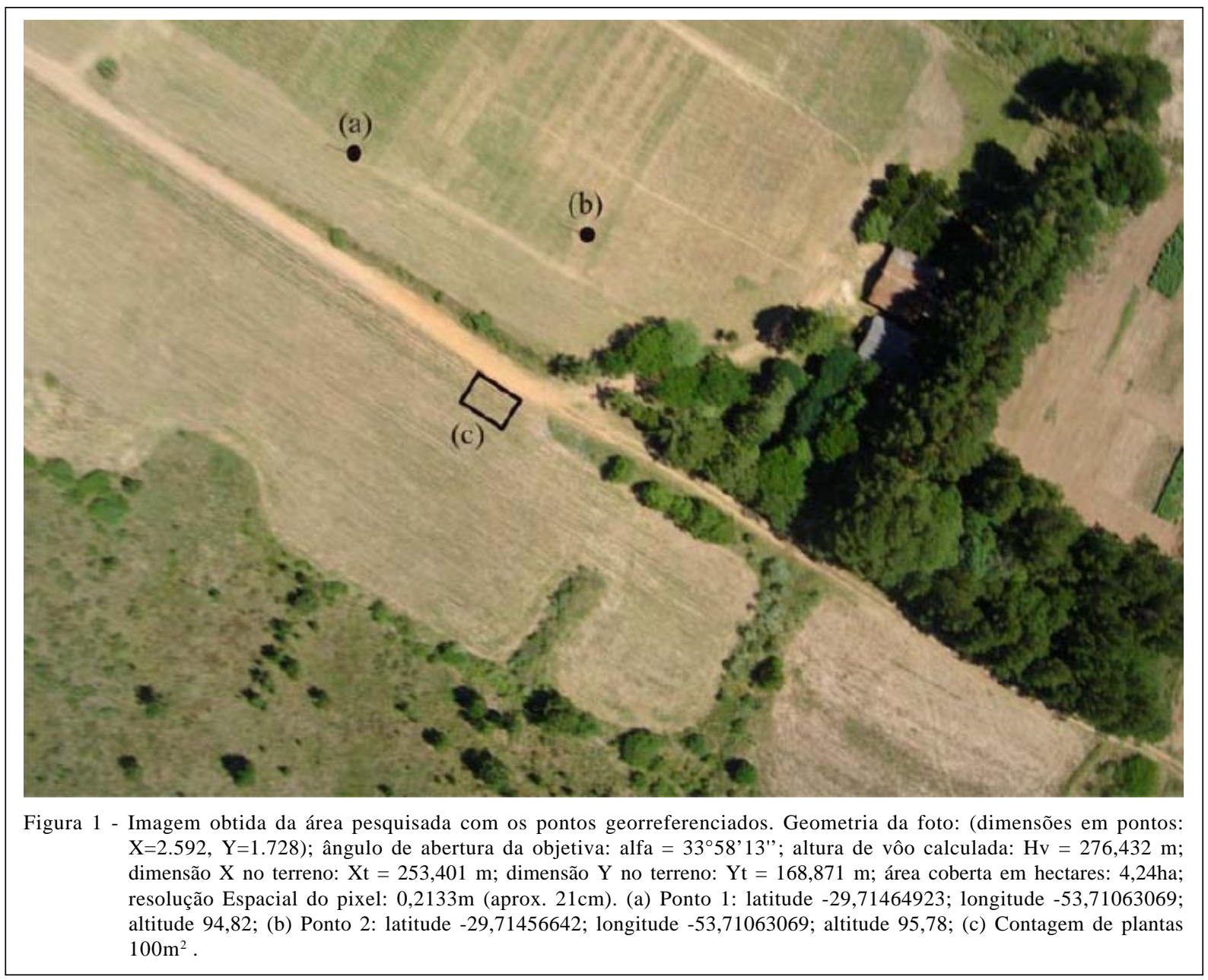

das culturas por meio das coordenadas (latitude e longitude e altimétrica) e o controle de velocidades e altitude de vôo. A precisão dos dados adquiridos em vôo está relacionada com o número dos sinais transmitidos pelos satélites e captados no GPS, estando diretamente relacionado com as condições meteorológicas. Outro fator que interfere na precisão das imagens é o eixo de coordenadas da câmera que, nesse caso, está alocado transversalmente à linha longitudinal do VANT.

Nas imagens aéreas, não foi possível realizar a contagem de plantas em falhas identificadas na lavoura devido à falta de equipamento adequado para a coleta. Porém, face à identificação do problema, foi possível, com auxílio de GPS em terra, identificar o local onde o mesmo havia sido detectado e assim estudar o caso in loco. Esta ferramenta pode ser útil, pelo menos, no processo preliminar de diagnóstico do problema, servindo como base para a implantação de estratégias emergenciais, como a visita a campo da área monitorada. Uma técnica a ser mais bem estudada seria o uso destas imagens para confecção de mapas de aplicação de defensivos em taxas variáveis, pela identificação de níveis de infestação na área. Porém, um dos principais empecilhos a este tipo de uso seria a precisão da localização geográfica dos pontos. Quanto ao uso em monitoramento de insetos desfolhantes e/ ou doenças comprometedoras de área foliar, a questão é encontrar um tratamento de imagem que consiga diagnosticar baixos níveis de desfolhamento ou infestação.

A altura de vôo também deve ser melhor estudada, visto que algumas dificuldades podem ser supridas corrigindo-a. Assim, se define a melhor cobertura em função do objetivo a ser alcançado. Um próximo passo talvez seja obter imagens em diferentes alturas de vôo, traçar planos de vôo diferenciados e correlacionar imagens obtidas com imagens de satélite, por exemplo.

As imagens aéreas verticais apresentaram bons resultados quanto ao número de informações observadas, podendo ser ampliadas para um melhor 
aproveitamento. Porém, a câmera fotográfica utilizada demonstrou não ser apropriada para esse tipo de trabalho. O equipamento desenvolvido mostrou imenso potencial para ser utilizado como ferramenta auxiliar na localização de áreas com falhas de germinação, de semeadura, com infestação de invasoras, mapeamento da área, etc., mesmo que ainda bastante dependente de instrumentos que proporcionem maior qualidade das imagens obtidas. Próximos trabalhos devem prever tratamentos que melhorem a qualidade das imagens e correlações com atributos da vegetação existente.

\section{REFERÊNCIAS}

ALONÇO, A. dos S. et al. Desenvolvimento de um veículo aéreo não tripulado (VANT) para utilização em atividades inerentes à agricultura de precisão. In: CONGRESSO
BRASILEIRO DE ENGENHARIA AGRÍCOLA, 35., 2005, Canoas. Anais... Jaboticabal: Associação Brasileira de Engenharia Agrícola, 2005. 1 CD-ROM.

ANTUNIASSI , U.R.; SALVADOR, A. Análise de imagens aéreas para mapeamento de plantas daninhas em sistemas de agricultura de precisão. In: SIMPÓSIO INTERNACIONAL DE AGRICULTURA DE PRECISÃO, 2., 2002, Viçosa. Anais... Viçosa: UFV, 2002. 1 CD-ROM.

MOLIN, J.P. Geração e interpretação de mapas de produtividade para a agricultura de precisão. In: BORÉM, A. et al. Agricultura de precisão. Viçosa: UFV, 2000. p.237-257.

MOREIRA, M.A. Fundamentos do sensoriamento remoto e metodologia de aplicação. 2.ed. Viçosa: Universidade Federal de Viçosa, 2003. 307p.

TSCHIEDEL, M.; FERREIRA, M.F. Introdução à agricultura de precisão: conceitos e vantagens. Ciência Rural, v.32, n.1, p.159-163, 2002. 